Gut, 1988, 29, 655-658

Liver and biliary

\title{
Recurrence and re-recurrence of gall stones after medical dissolution: a longterm follow up
}

\author{
L D J O'DONNELL AND K W HEATON \\ From the University Department of Medicine, Bristol Royal Infirmary, Bristol
}

\begin{abstract}
SUMMARY One hundred patients with radiolucent gall stones $\leqslant 1.5 \mathrm{~cm}$ in functioning gall bladders have received oral bile acid dissolution therapy since 1975. Complete data are available on 93 who have received at least six months' treatment. The complete dissolution rate in appropriately selected patients who complied with and tolerated an adequate course of treatment was $55 \%$. By life table analysis the recurrence rates were $13 \%$ at one year, $21 \%$ at two years, $31 \%$ at three years, and $43 \%$ at four years. Thereafter the recurrence rate levelled out, being $49 \%$ at 11 years. Redissolution was achieved in all seven patients who had a second course of therapy, but was usually followed by rerecurrence. Patients whose gall stones recurred did not differ significantly from those who remained stone free with respect to age, sex, body weight, or time required for dissolution.
\end{abstract}

Although the treatment of gall stones with a bile acid
mixture had been reported as early as $1937,{ }^{1}$ it was
not until the first descriptions of gall stone dissolution
by pure chenodeoxycholic acid (CDCA) in $1972^{23}$
that this mode of therapy entered clinical practice.
Since then there have been numerous advances in the
medical treatment of gall stones. The optimum
patient selection criteria and drug dosage have been
defined. A second agent, ursodeoxycholic acid
(UDCA) which has a number of advantages over
CDCA has been introduced. ${ }^{4}$ Ultrasonography
is now widely used in the diagnosis and monitoring
of gall stone disease and provides information
complementary to that obtained from oral
cholecystography.
Recurrence of gall stones after successful dissolu-
tion is common and is a major disincentive to
treatment.' The longterm outcome of successfully
treated patients is ill defined, however, as is the best
way to manage recurrences. The factors determining
recurrence are also unknown. Over the past 11 years
100 patients with gall stones have had medical
treatment in this unit according to the currently
accepted 'best' mode of therapy. In this article we
describe this experience with particular regard to

Address for correspondence: Dr K W Heaton. Dept of Medicine, Bristol Royal Infirmary, Bristol BS2 8HW.

Received for publication 9 November 1987. recurrence after dissolution and to redissolution of recurred stones.

\section{Methods}

PATIENTS

Patients with radiolucent gall stones $\leqslant 1.5 \mathrm{~cm}$ in diameter in gall bladders which opacified on oral cholecystography were treated with CDCA $15 \mathrm{mg} / \mathrm{kg}$ body weight $(n=75)$ or UDCA $10 \mathrm{mg} / \mathrm{kg}(\mathrm{n}=9)$ or a combination of CDCA $8 \mathrm{mg} / \mathrm{kg}$ and UDCA $5 \mathrm{mg} / \mathrm{kg}$ $(n=16)$. Chenodeoxycholic acid was taken at bedtime and UDCA either at bedtime or, since early 1986, in three divided doses daily. Between 1979 and 1982 UDCA was substituted for CDCA in patients who had the irritable bowel syndrome or who developed diarrhoea on CDCA alone. After 1982 such patients were given the combination of CDCA and UDCA and recently this has been first choice treatment for most patients. Obese patients were always asked to lose weight and were referred to a dietitian.

Follow up assessments were made at least every six months and consisted of clinical appraisal, oral cholecystography or ultrasonography, and since 1985 combined oral cholecystography and real time ultrasonography. Disappearance of gall stones was always confirmed by a second normal cholecystogram and, latterly, a second normal ultrasound scan done after a 
further three months of treatment. Partial dissolution was defined as a decrease in size of gall stones compared with previous imaging. All radiology results were reviewed by a consultant radiologist as well as the treating physician.

Patients who had successful dissolution of their gall stones were followed up by annual cholecystogram or, in recent years, ultrasound scan. Recurrence was defined as typical appearances of gall stone on cholecystography or ultrasonography.

Twenty five patients were entered into the British/ Belgian Gallstone Study Group's postdissolution trial and were randomised to placebo, to low dose UDCA $(3 \mathrm{mg} / \mathrm{kg} /$ day) or to high fibre, low refined carbohydrate diet. They are included because, in this trial, ${ }^{8}$ neither diet nor low dose UDCA significantly affected the recurrence rate.

Between 1975 and February 1987, 100 patients (mean age 55 years, range $20-87 ; 84$ women) started bile acid dissolution therapy. Eighty two patients gave a history of typical biliary pain whereas the remaining 18 patients had vague abdominal pain or dyspepsia. Most of the patients were tertiary referrals to the gall stone clinic (60 from surgeons, 14 from other physicians), 15 were referred by general practitioners and 11 came from other sources. In 27 patients surgery was contraindicated because of coexisting medical problems; the remainder received medical treatment because of their strong desire to avoid surgery. Statistical tests used were $\chi^{2}$ (with Yates' correction for small numbers) and Student's $t$ test as appropriate.

\section{Results}

\section{DISSOLUTION}

Data are not available for four patients who started treatment within the last six months and three who have been lost to follow up. In the remaining 93 patients there were, including recurrences, 101 instances of gall stones. Complete dissolution was achieved on 47 occasions in 40 patients. Thus the intention-to-treat success rate was $47 \% /$ case and $43 \% /$ patient. The duration of therapy to achieve complete dissolution was 15 (10) months [mean (SD)]; $60 \%$ of dissolutions occurred within one year. Partial dissolution has occurred in seven patients still on treatment and it is too early to judge their final outcome. The causes of treatment failure are listed in the Table. The complete dissolution rate in appropriately selected patients who complied with and tolerated an adequate course of treatment was $55 \%$. This rises to $64 \%$ if currently treated patients with partial dissolution are included as being likely to progress to full dissolution.

Patients who had successful dissolution did not
Table Number of patients and reasons for failure of medical dissolution of gall stones

26 No reduction in size of gall stones on radiology after 12 months therapy or longer

6 Drug side effects, mostly diarrhoea

5 Severe or continuing symptoms leading to surgery

3 Failure of compliance

3 Initially unrecognised rim of gall stone calcification

2 Coincidental occurrence of cancers (bowel, breast)

1 Occurrence of pregnancy despite oral contraceptive therapy

differ significantly from those who failed to respond to therapy as regards age [54 (16) v $58(15) \mathrm{y}]$, sex, weight at the start of treatment [67.1 (12.5) v 68.7 $(12 \cdot 3) \mathrm{kg}]$ or weight lost during therapy $[2.4(3.9) v$ $3 \cdot 0(3 \cdot 8) \mathrm{kg}$ ].

\section{RECURRENCE}

By life table analysis the recurrence rate after successful dissolution was approximately $10 \%$ per annum for the first five years (Figure). Follow up of patients who remained stone free for five years showed no further recurrence. One patient has escaped recurrence for 11 years. Thus the recurrence rate in the long term is approximately $50 \%$. Postdissolution follow up data are available over a period of at least four years in 27 patients. Fourteen had stone recurrence in the first four years. The 13 patients who remained stone free did not differ significantly from the 14 who had recurrences with respect to age [52 (16) $v 53(17) \mathrm{yr}]$, sex, body mass index at beginning of follow up [24.9 (4.9) $v 25.1$ $(5 \cdot 3)$ ] change in body weight during follow up (4.85 $(4.85) v 1.34(5.35) \mathrm{kg}$ ], drug used in treatment nor in the length of treatment needed for initial dissolution [12 (7) $v 19$ (11) months]. Pregnancy or oral contra-

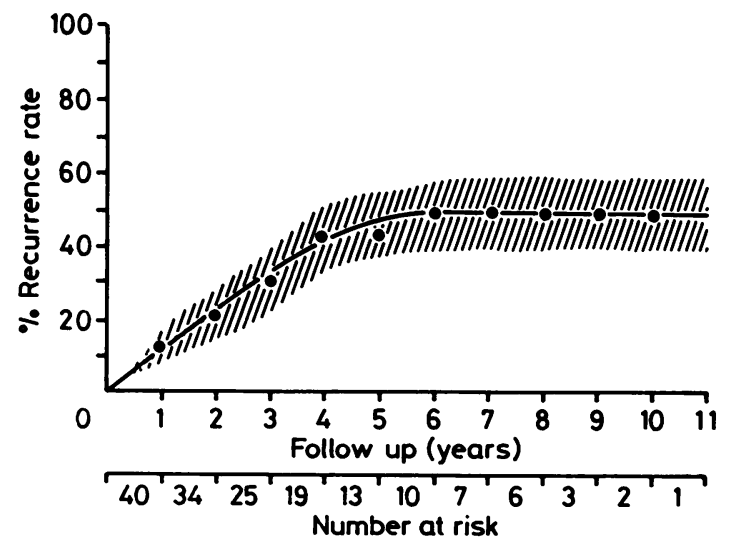

Figure Life table analysis of gall stone recurrence rate after medical dissolution. Shaded area represents standard error. 
ceptive use did not influence recurrence but the numbers involved were small.

DISSOLUTION OF RECURRENT STONES AND RERECURRENCE

Seven patients with recurrent stones opted for a second course of bile acid therapy. This led to complete redissolution in all seven. The patients were then followed up in standard fashion. One was lost to follow up. Re-recurrence was observed in four patients, in each case within 24 months of stopping treatment. Only two patients are known to be stone free, after 12 and 48 months of follow up. One patient with re-recurrence had a third course of bile acid therapy but when this had failed to produce dissolution of her gall stones within eight months she opted to have surgery.

\section{Discussion}

This study shows that, in appropriately selected patients, an adequate course of medical treatment produces complete dissolution of gall stones in up to $55 \%$ of cases and that approximately $50 \%$ of these patients can expect to remain stone free in the long term. Medical treatment of patients with recurrent gall stones is highly successful but further recurrence is likely after stopping treatment.

Using selection criteria similar to ours other workers have reported complete dissolution rates of $5-75 \% .^{+4-11}$ Low rates occurred when inadequate dosage of bile acids were used." High dissolution rates of $70-80 \%$ have been reported in studies with high exclusion rates. ${ }^{10}$ Previous reports of dissolution rates on an intention-to-treat basis are in accordance with our figure of approximately $45 \%$."

Because it takes into account patients who have been lost to follow up and also the variable periods of follow up, cumulative life table analysis is the best method for assessing the rate of postdissolution recurrence. Studies which have not used this method of analysis have reported 'recurrence rates' of between $17 \%$ and $50 \% .{ }^{72}$ Our results show that recurrence occurs at a rate of approximately $10 \%$ per annum for the first five years and is very uncommon thereafter. This confirms and extends the findings of a previous report with a shorter period of follow up..$^{13}$

We could not identify any clinical features which differentiate patients who recur from those who do not. Pregnancy and use of oral contraceptives, which are known risk factors for gall stones, occurred in only a small number of patients and not obviously more often in those who recurred than in those who remained stone free. Obesity too was not a predictive factor nor was weight loss during treatment but obese patients generally failed to lose weight.
Recurrence of gall stones after successful dissolution is not unexpected as, after cessation of bile acid therapy, bile reverts to being supersaturated in the vast majority of patients. ${ }^{1417}$ Only $50 \%$ of patients, however, get recurrence in the long term. This implies there are other factors besides supersaturation of bile which determine recurrence. Changes in gall bladder motor function, ${ }^{18} 19$ nucleating factors, ${ }^{20}$ and crystallisation inhibitors ${ }^{2122}$ are thought to be involved in the pathogenesis of gall stones. We suggest they are also important in determining whether gall stones recur and re-recur after successful dissolution. This hypothesis could be tested by doing the appropriate studies of bile and gall bladder function in patients whose gall stones dissolve and relating the findings to the subsequent outcome in terms of recurrence. Meanwhile, the most appropriate way to manage patients whose gall stones have been dissolved remains unknown.

Presented in part at the Autumn meeting of the British Society of Gastroenterology in Cardiff during September 1986, and published in abstract form: Gut 1986; 27: 1234A.

\section{References}

1 Rewbridge AG. The disappearance of gallstone shadows following the prolonged administration of bile salts. Surgery 1937; 1: 395-400.

2 Danzinger RG, Hofmann AF, Schoenfield LJ, Thistle JL. Dissolution of cholesterol gallstones by chenodeoxycholic acid. N Engl J Med 1972; 286: 1-8.

3 Bell GD, Whitney B, Dowling RH. Gallstone dissolution in man using chenodeoxycholic acid. Lancet 1972; ii: $1213-6$.

4 Iser JH, Dowling RH, Mok HY, Bell GD. Chenodeoxycholic acid treatment of gallstones - a follow up report and analysis of factors influencing response to therapy. N Engl J Med 1975; 293: 378-83.

5 Bachrach WH, Hofmann AF. Ursodeoxycholic acid in the treatment of choleserol cholelithiasis. Dig Dis Sci 1982; 27: 737-61; 833-56.

6 Gleeson D, Ruppin DC. Discrepancies between cholecystography and ultrasonography in the detection of recurrent gallstones. J Hepatol 1985; 1: 597-607.

7 Ruppin DC, Dowling RH. Is recurrence inevitable after gallstone dissolution by bile-acid treatment? Lancet 1982; i: 181-5.

8 Hood K, Gleeson D, Ruppin DC, Dowling RH, and the BBGSG. The British/Belgian Gallstone Study Group's (BBGSG) post dissolution trial. [Abstract]. Gut 1987; 28: A1359.

9 Schoenfield LJ, Lachin JM, Baum RA, et al. Chendiol (Chenodeoxycholic acid) for dissolution of gallstones: the national cooperative gallstone study. Ann Intern Med 1981; 95: 257-82.

10 Leuschner U, Leuschner M, Stromm WD, et al. Our 10 years' experience in gallstone dissolution. Comparison 
with the national cooperative gallstone study (NCGS, USA) and the Tokyo cooperative gallstone study (TCGS, Japan). [Abstract]. Gastroenterology 1982; 82: 1113.

11 Maton PN, Iser JH, Reuben A, et al. The final outcome of CDCA treatment in 125 patients with radiolucent gallstones: factors influencing efficacy, withdrawal, symptoms and side-effects and post dissolution recurrence. Medicine (Balt) 1982; 61: 86-97.

12 Ponz de Leon M, Carculli N, Iori R, Loria P, Smerieri A, Zironi F. Medical treatment of gallstones with chenodeoxycholic acid (CDCA): follow up report at four years. Ital J Gastroenterol 1980; 22: 17-22.

13 Lanzini A, Jazrawi RP, Kupfer RM, Maudgal DP, Joseph AEA, Northfield TC. Gallstone recurrence after medical dissolution. An overestimated threat? J Hepatol 1986; 3: 241-6.

14 Mok HY, Bell GD, Dowling RH. Effect of different doses of chenodeoxycholic acid on bile-lipid composition and frequency of side effects in patients with gallstones. Lancet 1974; ii: 253-7.

15 Thistle JL, Yu PY, Hofmann AF, Ott BJ. Prompt return of bile to supersaturated state followed by gallstone recurrence after discontinuance of chenodeoxycholic acid therapy. [Abstract]. Gastroenterology 1974; 66: 789.
16 Iser JH, Murphy GM, Dowling RH. Speed of change in biliary lipids and bile acid with chenodeoxychilic acid-is intermittent therapy feasible? Gut 1977; 18: 7-15.

17 Ruppin DC, Murphy GM, Dowling RH, et al. Gallstone disease without gallstones - bile acid and bile lipid metabolism after complete gallstone dissolution. Gut 1986; 27: 559-66.

18 Forgacs IC, Maisey MN, Murphy GM, Dowling RH. Influence of gallstones and ursodeoxycholic acid therapy on gallbladder emptying. Gastroenterology 1984; 87: 299-307.

19 Pomeranz IS, Shaffer EA. Abnormal gallbladder emptying in a subgroup of patients with gallstones. Gastroenterology 1985; 88: 787-91.

20 Burnstein MJ, Ilson RG, Petrunka CN, Taylor RD, Strasberg SM. Evidence for a potent nucleating factor in the gallbladder bile of patients with cholesterol gallstones. Gastroenterology 1983; 85: 801-7.

21 Sutor DJ, Percival JM. Presence or absence of inhibitors of crystal growth in bile. Effect of bile on the formation of calcium phosphate, a constituent of gallstones. Gut 1976; 17: 506-10.

22 Holan KR, Holzbach RT, Hermann RE, Cooperman AM, Claffey WJ. Nucleation time: a key factor in the pathogenesis of cholesterol gallstone disease. Gastroenterology 1979; 77: 611-7. 